\title{
SMART SENSOR MONITORING IN ENERGY CROP BIOMASS PRODUCTION
}

\author{
Nikola Dražićí, \\ Jela Ikanović2, \\ Gordana Dražić ${ }^{1}$
}

\author{
${ }^{1}$ Singidunum University, \\ Belgrade, Serbia \\ ${ }^{2}$ Independent University in Banja Luka, \\ Banja Luka, Republic of Srpska, BIH
}

\begin{abstract}
:
Sustainable biomass production is recognized as a key moment in the development of the European bioeconomy. In order for the production to be truly sustainable, a holistic approach is needed for research of new technologies and methods that are at the same time economically viable, environmentally friendly and socially acceptable. The approach of smart agriculture is based on the collection and processing of large databases that serve to understand crop reactions to the current environment and enable rational production planning. This paper gives a brief overview of IT used in agriculture with a focus on monitoring the biomass of energy crops in order to indicate the current level of development and potential application in the region. Biomass development monitoring is presented through the application of Data Acquisition Sensors, Biomass indexes and Data Processing And Analysis Methods. The current level of development of these technologies enables monitoring of biomass development (primarily through the vegetation index and crop height) in real time and in the selected area. The data collected in this way are used to predict and take adequate agro-technical measures at the right time, which leads to high stable yields.
\end{abstract}

Keywords:

Biomass, smart agriculture, big data processing.

\section{INTRODUCTION}

Sustainable biomass production is recognized as a key moment in the development of the European bioeconomy [1]. In order for this production to be truly sustainable, a holistic approach is needed for research of new technologies and methods that are at the same time economically viable, environmentally friendly and socially acceptable, ie contribute to the rural development of local communities or wider regions. The yield per unit area of land is of the utmost importance. In order to achieve satisfactory yields, it is necessary to maximize the biorational use of biological resources - genetic, special and ecosystem [2]. This means that the development of biomass of different crops and their varieties should be monitored, in locations that differ in climatic and pedological characteristics and under the influence of various biological factors, and
Correspondence:

Nikola Dražić

e-mail:

n.drazic@yahoo.com 
then appropriate biotechnical measures should be determined on that basis. It is also necessary to determine the time dimension of biomass development in order to determine the application of certain biotechnical measures (fertilization, irrigation) and the optimal harvest time.

This requires detailed monitoring of biomass development, which includes frequent field visits and extensive measurements of various biometric characteristics that determine the final yield $[3,4]$. This approach, in addition to requiring a cumbersome workforce, is often not able to provide all the necessary data because field monitoring is not common enough in space and time to reduce costs. In order to overcome these challenges, in recent years the approach of smart agriculture has been intensively developed, which is based on the collection and processing of large databases that serve to understand crop reactions to the current environment and enable rational production planning. New approaches relate to innovative digital technologies that enable the collection, storage and modelling of vast amounts of data [5]. This usually takes place through several steps: 1) Detection of local parameters of biomass development, 2) Identification and detection of the selected location, 3) data transfer from the field - farm to the control station and 4) decision making on the application of agrotechnical measures based on collected data, and previous experiences, and 5) activation of selected measures. For the realization of the whole process, strong cooperation of experts in the field of biology, ecology, farming and IT is necessary.

This paper gives a brief overview of IT used in agriculture with a focus on monitoring the biomass of energy crops in order to indicate the current level of development and potential application in the region.

\section{BIOMASS DEVELOPMENT MONITORING}

A recently published detailed review of 126 literature sources not older than 2017 related to UAS (unmanned aerial systems) indicates the relevance of research in this field [6]. UAS is a low cost, fast and non-destructive method for remote sensing testing of crop biomass development that enables non-contact monitoring by collecting data on spectral, textural and structural characteristics of fields on very wide temporal and spatial scales, and we focus on those related to farms. They consist of a platform, autopilot, mechanical steering components, sensors for navigation and data collection.

\subsection{DATA ACQUISITION SENSORS}

The most specific component that determines the applicability of UAS is Data Acquisition Sensors. These sensors can be classified into several groups; RGB, multispectral, and hyperspectral sensor work on the same principle. During development, crops adapt to current environmental conditions by changing the characteristics of the photosynthesis process, which is reflected in the spectrum of reflected light from the leaf surface. These changes are in the intensity of individual spectral bands, ie reflections of certain wavelengths, so based on their relationships, plants that are in some kind of environmental stress (usually lack of moisture or nutrients - primarily nitrogen) can be distinguished from plants that develop optimally. Similarly, plants that suffer from a disease can be distinguished from healthy plants. Also, during the ontogenetic development of plants, the expected spectral changes occur, which enabled the monitoring of crop phenophases using appropriate sensors.

The simplest, cheapest and least accurate are RGB sensors (which measure the intensity of only three colours (red, green and blue) in each pixel of a colour image. Low cost is the reason for their widespread use in monitoring biomass development. Multispectral sensors, unlike RGB, also track near-infrared spectral lines that are important for understanding physiological processes in the plant, but are significantly more expensive. Hyperspectral sensors provide an even more accurate panchromatic image. Their disadvantage is the high cost on the one hand and too much data which are not always necessary and their processing is extremely demanding and generally not possible using existing algorithms. Figure 1 shows the relationship between spectral characteristics and plant condition [7].

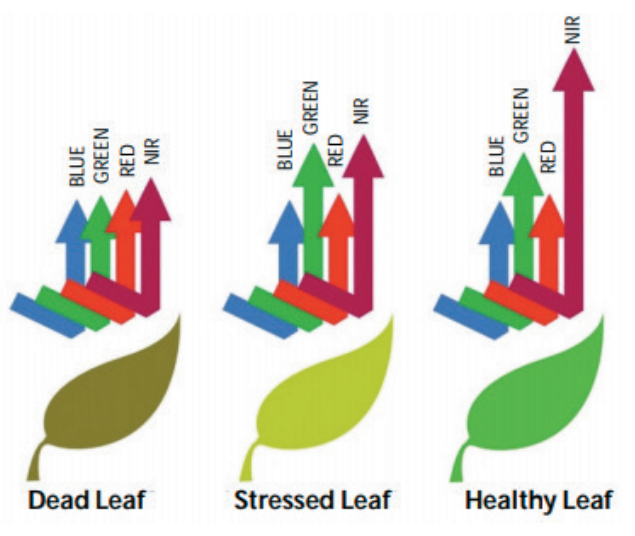

Figure 1 - Spectral characteristics of leaves in different conditions [7] 


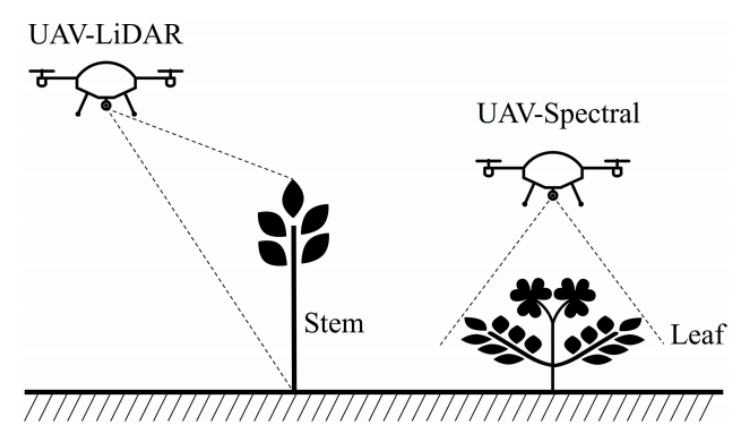

Figure 2 - Schematic illustration of the difference between LiDAR and spectral data [8]

Spectral sensors are subject to interference from the environment, so they do not always provide enough necessary data. Therefore, depth sensors have been developed, primarily LiDAR (Light Detection and Ranging), which work on the principle of measuring distance by analysing the return energy of emitted laser pulses. The best results can be achieved by a wise combination and fusion of data obtained using spectral and depth sensors

\subsection{BIOMASS INDEXES}

The most used biomass indicators are VI (vegetation indexes) and $\mathrm{CH}$ (crop height) and are obtained from images or three-dimensional point clouds of crops.

VIs are used to monitor the condition of vegetation on a surface and give answers about its presence, diversity and condition. Different monitoring and calculation methods have been developed, of which the most commonly used is the normalized difference vegetation index (NDVI), which is calculated from the reflection ratio in the near infrared range and the red range, according to a simple formula. They are often combined with mage texture information.

Crop height is in a high positive correlation with the development of biomass in the vast majority of agro-energy crops, so it is a suitable parameter that is monitored using RGB sensors and multispectral sensors I LiDAR. Data are processed by various methods and inserted into prognostic models. Figure 3 shows an example of the results for the development of maize biomass obtained by applying various techniques [8]. In this case, too, due to the complexity of real situations in the field, a combination of these techniques is recommended, which must be modified in relation to each tested species.

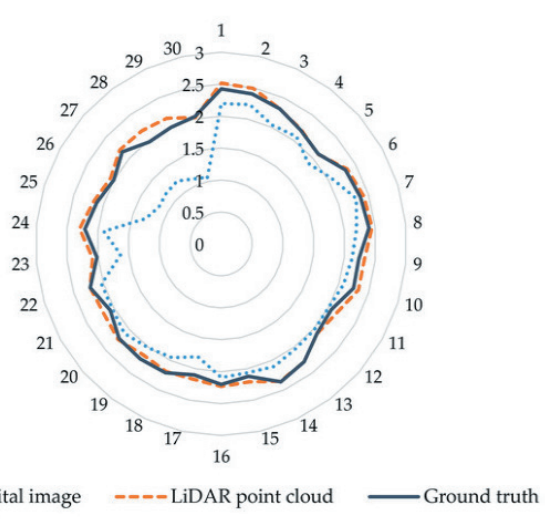

Figure 3 - Comparison of accuracy of maize plant height extracted from digital and LiDAR data [8].

\section{DATA PROCESSING AND ANALYSIS METHODS}

Sensor-generated data must be processed to be useful in biomass monitoring. Pre-preparation refers to the corrections of the images themselves and the fan data analysis is performed using Machine learning algorithms. Biomass development is a typical regression problem that can be solved by various algorithms, some of which are relatively simple and others very demanding. The most commonly used are: Support Vector Regression (SVR), Random Forest Regression (RFR), Artificial Neural Network (ANN), Multiple Regression Techniques [9]. The use of advanced algorithms such as machine learning algorithms enables the construction of highly efficient models of biomass energy crop development that use data from low cost sensor devices.

Figure 4 shows an example of a data processing diagram developed to monitor changes in the structure of canopy sorghum. Using this protocol, good agreement was obtained with the results from the field in the domain $\mathrm{CH}$ and VI for both examined approaches (LiDAR and RGB), but the best agreement was obtained by their combination. Although the high potential of the applied techniques in determining the state of sorghum biomass has been proven in this case as well, certain limitations in relation to the density and phenophase of crops have been observed [10]. 


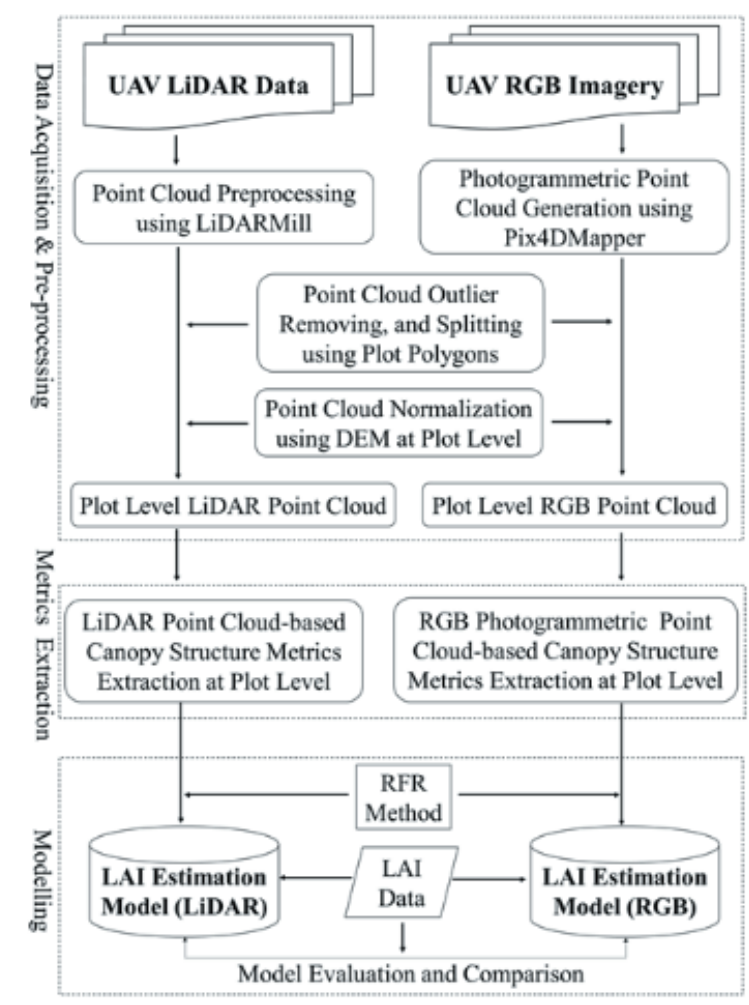

Figure 4 - Diagram of data processing and modelling for sorghum biomass [10].

Research and development of these methods are primarily focused on application models that are rapidly appearing on the market. From a research point of view, these technologies are in the early stages of development and show many advantages but also limitations. Namely, the obtained results are often not comparable even if it is the same crop, because they appear in different formats. On the other hand, when comparing the application of the method, it is noticed that different authors recommend different combinations of Data Collection and Processing Systems, which are often contradictory.

In order to overcome such problems, intensive research is conducted through case studies and comparisons of results with the results of classical tests. Figure 5 shows an example of comparing 3 predictive models of forage crop biomass testing that differ in the level of generalization. The Green Normalized Difference Vegetation Index (GNDVI) was developed in two directions in relation to small and large values of fresh and dry mass of the biomass sample of forage crops and in relation to the vegetation cover cluster. All three models allow fine spatial resolution. In this case, the use of RGB imagery gave better agreement with the data collected by conventional methods of sampling and characterization of biomass compared to volumetric measurement because it allows to distinguish between living and dead biomass (ie photosynthetically active and dried plants) [11]. Such models are suitable for monitoring the spatial distribution of biomass but are not sufficiently usable in relation to the time scale.

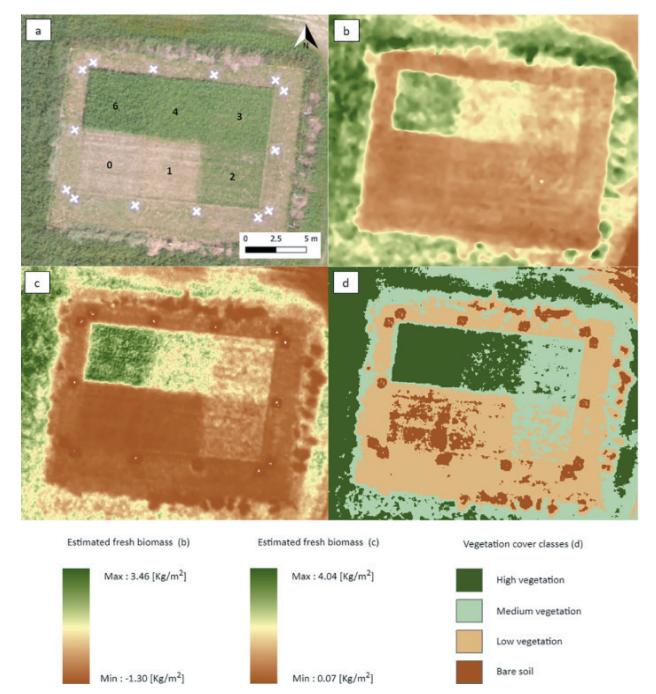

Figure 5 - Comparison of the representation of the same experimental field of sorghum by different models:

a - RGB, b - volumetric model, c - GNDVI for biomass, d - GNDVI for vegetation cover [11]

\section{CONCLUSION}

Sustainable development of agriculture, and production of agro-energy crops (and crop residues) as a renewable energy source in the form of biomass, requires the application of IT. Innovative methods, which include a number of techniques for collecting and processing a large amount of data on biomass development in the field, enable the approximation of sustainability through their application both in research and development programs and on the farm. As this is a relatively new approach, the methods are still being improved so that there is no universal model that would be applicable to a large number of crops and environmental conditions, which is to be expected given their biological diversity. The current level of development of these technologies enables monitoring of biomass development (primarily through the vegetation index and crop height) in real time and in the selected area. The data collected in this way are used to predict and take adequate agro-technical measures at the right time, which leads to high stable yields. 


\section{ACKNOWLEDGEMENTS}

The research was supported by the Ministry of Education, Science and Technological Development of the Republic of Serbia (contract No 0801-417/1).

\section{REFERENCES}

[1] N. Scarlat, "Highlights of the Conference" In Proceedings of the 27th European Biomass Conference \& Exhibition, 2019, Lisbon, Portugal, http://programme.eubce.com/search.php?.close=all

[2] M. Von Cossel, M. Wagner, J. Lask, E. Magenau, A. Bauerle, V. Von Cossel, K. Warrach-Sagi, B. Elbersen, I. Staritsky, M. Van Eupen, Y. Iqbal, N.D. Jablonowski, S. Happe, A.L. Fernando, D. Scordia, S.L. Cosentino, V. Wulfmeyer, I. Lewandowski, and B. Winkler, "Prospects of Bioenergy Cropping Systems for A More Social-Ecologically Sound Bioeconomy", Agronomy, Vol. 9, 605. 2019, Doi: 10.3390/agronomy9100605

[3] G. Drazic, J. Milovanovic, J. Ikanovic, and I. Petric, "Influence of fertilization on Miscanthus $x$ giganteus (Greef et Deu) yield and biomass traits in three experiments in Serbia". Plant Soil Environ., Vol. 63, pp 189-193, 2017, https://doi. org/10.17221/156/2017-PSE

[4] N. Rakašćan, G. Drazić, V. Popović, J. Milovanović, LJ, Zivanović, M. Aćimić Remikovic, T. Milanovic, and J. Ikanovic, "Effect of digestate from anaerobic digestion on Sorghum bicolor L. production and circular economy", Not Bot Horti Agrobo. Vol. 49, no 1, 12270, 2021, 2021DOI: https://doi. org/10.15835/nbha49112270

[5] A. Lytosa, T. Lagkas, P. Sarigiannidis, M. Zervakis, and G. Livanose, "Towards smart farming: Systems, frameworks and exploitation of multiple sources", Computer Networks, Vol. 172, 107147, May 2020, https://doi.org/10.1016/j.comnet.2020.107147

[6] T. Wang, Y. Liu, M. Wang, Q. Fan, H. Tian, X. Qiao, and Y. Li, "Applications of UAS in Crop Biomass Monitoring: A Review”, Front. Plant Sci. 12:616689. 2021, doi: 10.3389/fpls.2021.616689

[7] G. Sylvester (2018) „E-agriculture in action: drones for agriculture", Food and Agriculture Organization of the United Nations and International Telecommunication Union, Bangkok, 2018, ISBN 978-92-5-130246-0s

[8] Y, Zhu, C, Zhao, H, Yang, G. Yang, L. Han, Z. Li, H. Feng, B. Xu, J. Wu, and L. Lei. "Estimation of maize above-ground biomass based on stem-leaf separation strategy integrated with LiDAR and optical remote sensing data" Peer J. 7:e7593, Sept. 2019, https://doi.org/10.7717/peerj.7593
[9] L. Ma, Y. Liu, X. L. Zhang, Y. X. Ye, G. F. Yin, and B. A. Johnson, "Deep learning in remote sensing applications: a meta-analysis and review". ISPRS J. Photogramm. Remote Sens. Vol. 152, pp. 166-177, 2019, doi: 10.1016/j.isprsjprs.2019.04.015

[10] M. Maimaitijiang, V. Sagan, H. Erkbol, J. Adria, M. Newcomb, D. LeBauer, D. Pauli, N. Shakoor, and T. C. Mockler, "UAV-based sorghum growth monitoring: a comparative analysis of lidar and photogrammetry", ISPRS Annals of the Photogrammetry, Remote Sensing and Spatial Information Sciences, Volume V-3-2020, 2020 XXIV ISPRS Congress (2020 edition), 10.5194/isprs-annalsV-3-2020-489-2020

[11] J. Théau, E. Lauzier-Hudon, L. Aubé, and N. Devillers, "Estimation of forage biomass and vegetation cover in grasslands using UAV imagery". PLoS ONE, Vol. 16, no 1, e0245784, Jan. 2021 https://doi. org/10.1371/journal.pone.0245784 